\title{
Russian summer tops 'universal' heatwave index
}

Proposed definition of heatwaves grades 2010 Russia event the worst on record.

Hannah Hoag

29 October 2014

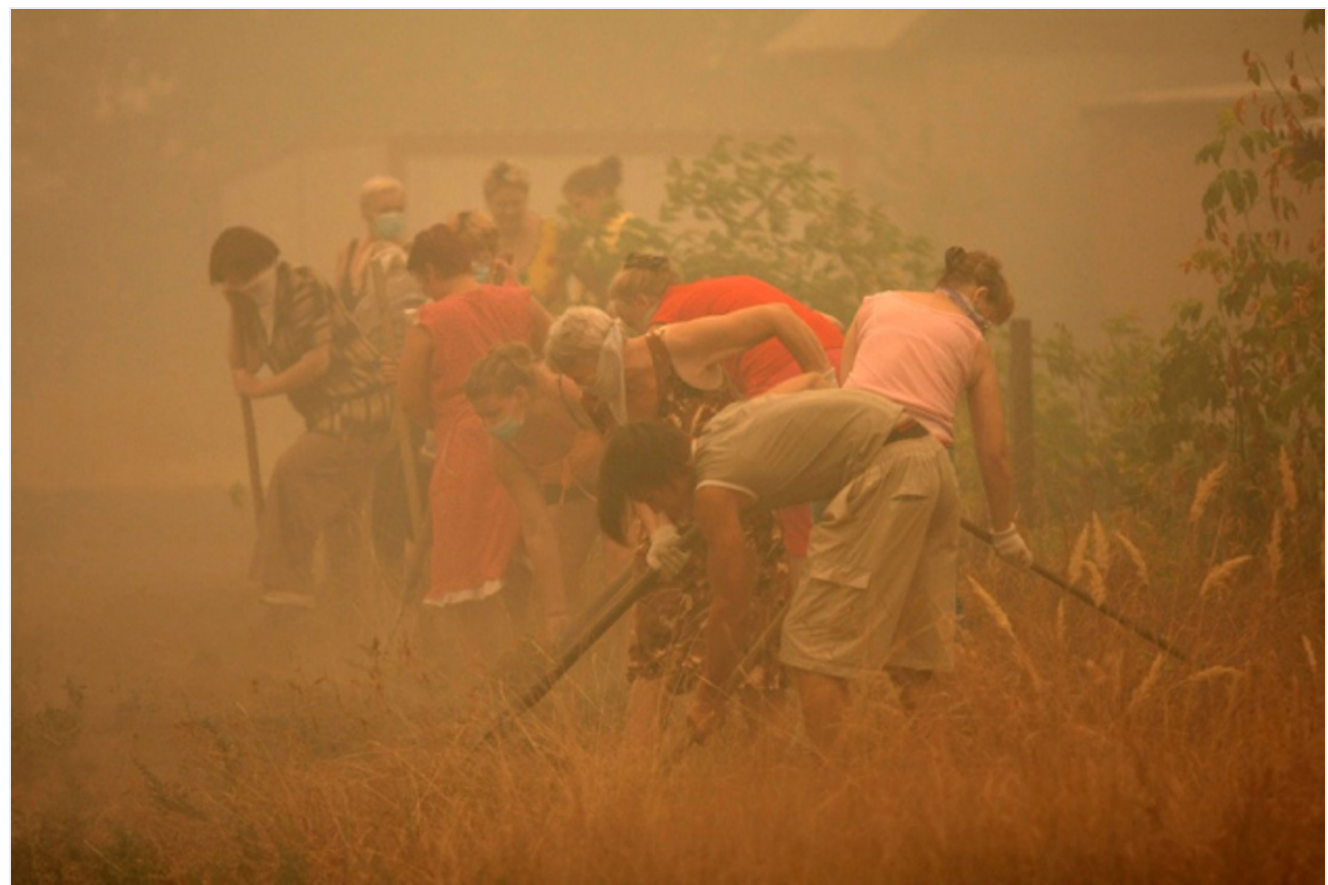

ANDREY SMIRNOV/AFP/Getty Images

People dig a ditch near Mokhovoye, a town 130 kilometres outside Moscow, to protect themselves from fires that raged during the 2010 heatwave.

The torrid weather that choked western Russia in the summer of 2010 , killing an estimated 55,000 people, was by far the worst such event of the past 33 years, according to a climate index that scientists have devised to gauge the magnitude of heatwaves. The index, which takes into account the severity of temperature extremes as well as the duration of the heatwave, could become a benchmark for evaluating the impacts of future climate change.

The Heat Wave Magnitude Index (HWMI), described this week in the Journal of Geophysical Research: Atmospheres ${ }^{1}$, merges several climate-related measurements of intense heat events into a single number that enables researchers to compare heatwaves that have occurred in different regions and in different years. 
"Like magnitude for earthquakes, this is a scale that is valid around the world and in different climate conditions," says physicist Simone Russo of the European Commission's Joint Research Centre in Ispra, Italy, and the study's lead author.

\section{Better view}

According to climatologist Erich Fischer of the Swiss Federal Institute of Technology in Zurich, Switzerland, who was not involved in the study, other indices have failed to capture the complexity of heatwaves. The Warm Spell Duration Index, for example, ranks them on the basis of the number of days for which temperatures stay above a given threshold. According to that index, a 20-day heatwave with daily maximums $0.1{ }^{\circ} \mathrm{C}$ above the threshold would be considered more severe than a 10 -day heatwave with maximum temperatures $5{ }^{\circ} \mathrm{C}$ above the threshold.

"There is a long-standing problem that there is no universal definition for a heatwave," says Fischer. "A lot of the impacts of a heatwave depend on the combination of the intensity of the heat and its persistence. This new index is more comprehensive."

The HWMI incorporates analyses of daily maximum temperatures for unusually warm days (compared to a reference period from 1981 to 2010) and their duration. It groups heatwaves into seven categories, ranging from normal (HWMl greater than 1) to ultra extreme (HWMl greater than 32$)$.

The index classifies the 2010 Russian heatwave and one that hit the US in 1980 as extreme events, earning median scores of 5.43 and 4.10 , respectively, compared with 3.48 for the 2003 European heatwave, which may have killed more than 70,000 people $^{2}$.

Sarah Perkins, a climate scientist at the University of New South Wales in Sydney, Australia, calls the index useful, but says it could be improved, for instance, by taking into account daily minimum temperatures and not just maximum ones. "When it comes to human health, if you don't have cooler night-time temperatures with hot days, then you get quite sick," she says.

\section{Warmer outlook}

To see how future heatwaves will compare with past ones on the basis of their new measure, Russo and colleagues projected the frequency and severity of the events throughout the twenty-first century, based on a variety of climate-change models.

Under a 'moderate' scenario of climate change known as RCP4.5 (see 'The range of future climates'), the researchers project that during the years 2020-2052, a number of regions in the United States, Europe and Africa will each experience at least one extreme heatwave. In the same period, parts of northern South America, Africa, the United States and southern Europe could have three such events. By 2100 , the study finds, Europe and the United States could experience heatwaves rivalling their worst previous ones every two or three years.

If greenhouse-gas emissions continue to rise at current rates and the increase in global mean temperatures approaches $4{ }^{\circ} \mathrm{C}$, the United States and Europe could experience 'very extreme' heatwaves (HWMl greater than 8) every one or two years and 'super extreme' heatwaves (HWMl greater than 16) once every ten years by the end of the century, according to the study.

The projections are consistent with earlier research, says Dim Coumou, a climate scientist at the Potsdam Institute for Climate Impact Research in Germany. "Heatwaves are on the rise," he says, highlighting the Mediterranean and tropical regions. "In the future, this is going to continue."

Nature | doi:10.1038/nature.2014.16250

\section{References}

1. Russo, S. et al. J. Geophys. Res. Atmos. http://dx.doi.org/10.1002/2014JD022098 (2014).

2. Robine, J.-M. et al. Comptes Rendus Biologies 331, 171-178 (2008).

Nature ISSN0028-0836 ESSN 1476-4687

\section{SPRINGER NATURE}

